\title{
Epidemiological aspects of the incidence of endometrial cancer in the city of Tashkent
}

\author{
Atakhanova N.E , Tursunova N.I \\ Department of Oncology, Tashkent Medical Academy, 100109, Almazar district, Faroby 2, Tashkent, Uzbekistan \\ Address for correspondence: Prof. Atakhanova Nigora Ergashevna, Department of Oncology, Tashkent Medical \\ Academy, 100109, Almazar district, Faroby 2, Tashkent, Uzbekistan, e-mail: nigora_atakhanova@tma.uz
}

Received February 28, 2019; Accepted March 17, 2019

Endometrial cancer is one of the most common diseases of the female genital area. Annually in the world more than half a million new cases of uterine body cancer are registered. The purpose of the research was to study morbidity, mortality and survival of urban patients with endometrial cancer residing in Tashkent. The incidence of endometrial cancer is increasing every year, but there is a relative stability of mortality rates and an increase in the 5-year survival rate in Tashkent.

Key Words: endometrial cancer, morbidity, mortality, 5-year survival.

\section{INTRODUCTION}

Endometrial cancer (EC) is a serious oncological problem, annually in the world this diagnosis is made by more than 287 000 women, 73800 die from this disease. ${ }^{1}$ Due to the current level of health development in developed countries, $75 \%$ of cases of EC are detected early in the course, ${ }^{2}$ when patients can be successfully treated, so in general, with an incidence rate of 12.9 per 100000 , the death rate is 2.4 per 100000 female population per year. ${ }^{1}$

In the United States of America (USA), 34000 women are diagnosed each year with uterine cancer, of which 6000 die from this disease. Annually, the incidence of cancer of the body of the uterus in the US, Italy, Israel, Sweden and Germany is 20; 20; 20.6; $20.7 ; 23.2 \%$ respectively. Japan has the lowest incidence of this pathology, 1.4; India - 2.0; Spain - 7.1. ${ }^{3}$

Rates of mortality from cancer of the uterus body in different countries are strictly different. In Western Europe, the incidence and mortality from cancer of the uterus body occupy the $7^{\text {th }}$ place among the morbidity and mortality rates from malignant tumors in women, their part in the overall mortality is $1-2 \%$. In the countries of the European Union, every year 81 500 women get cancer of the body of the uterus, and this indicator is growing every year. The average age is 60 years and above. The death rate for every 100 thousand of the female population is in Brazil - 6.1, Great Britain - 12.8, Italy - 11.7, Germany - 21.0, Japan - 1.3. ${ }^{4}$

The incidence of endometrial cancer in the age range from 40-44 years to 50-54 years makes a sharp jump, increasing about 4 times, gradually reaching a peak by the period of 60-64 years, after which it decreases markedly. At the age of more than 75 years, it is approximately half the "peak values". ${ }^{5}$ In Asian countries, the incidence of uterine body cancer is generally lower than in the
North American continent and the territories of Western and Northern Europe, and although there are relatively few such data, immigrants of Chinese and Japanese origin have already increased for the first few decades. ${ }^{6}$

The purpose of the study was to study morbidity, mortality and survival of urban patients with endometrial cancer residing in Tashkent on the basis of cancers register data.

The material for the study

The material for the study was information about patients, information about which is included in the section "Cancer of the body of the uterus" of the cancers register of the Tashkent city branch of the Republican Specialized Scientific and Practical Medical Center of Oncology and Radiology. Morbidity (a rough intensive indicator) was calEClated from 2007-2017. according to the formula:

$$
\mathrm{C}=\mathrm{R} / \mathrm{N} \cdot 100,000,
$$

where $\mathrm{C}$ - is a rough intensive incidence rate, $\mathrm{R}$ - is the number of sick women, $\mathrm{N}$-is the number of female population in the studied year.

Mortality (a rough intensive indicator) for a similar formula was calEClated from 2007 to 2017.

\footnotetext{
This is an open access journal, and articles are distributed under the terms of the Creative Commons Attribution-NonCommercial-ShareAlike 4.0 License, which allows others to remix, tweak, and build upon the work non-commercially, as long as appropriate credit is given and the new creations are licensed under the identical terms.
}

For reprints contact: weda-h@ weda-h.org

How to cite this article: Atakhanova NE, Tursunova NI. Epidemiological aspects of the incidence of endometrial cancer in the city of Tashkent. J ADV HEALTH 2019; 1(2): 149-151. 
The total observed survival rate was calculated using the Kaplan-Mayer method (1054 patients) from 2007-2017.

A log-rank method was used to compare the groups. The data was checked using the Cox-Mantel method, and the confidence interval was estimated using the Greenwood formula.

From 2008 to 2012, the incidence of EC in the city increased 1.2 times: from 35.4 to 41.9 per 100000 female population. But as can be seen from Fig. 1. 2013, this indicator decreased to 38.7 per 100000 female defilements, gradually rising to 40.9 in 2015 and then again decreased 1.12 times - 36.4 per 100000 population in 2016 .

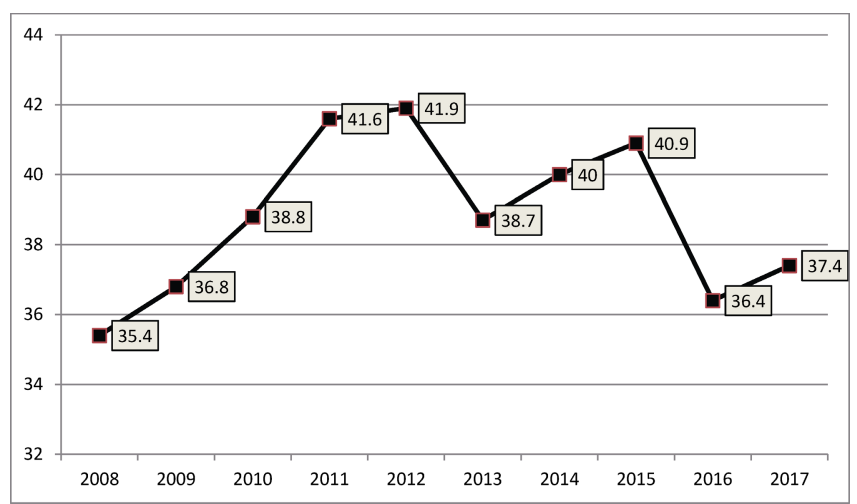

Figure 1. Incidence of EC in Tashkent from 2008 to 2017

\section{Analyzing the static indicators for mortality of uterine body} cancer

we should note a fairly high rate in 2009 - 3.1 per 100000 population over a tenth summer period (2008-2017). In Fig. 2 shows that since 2010 mortality decreased, and in 2016 a rough intensive indicator was 1.8, which may indicate an increase in the effectiveness of treatment of endometrial cancer in the city of Tashkent.

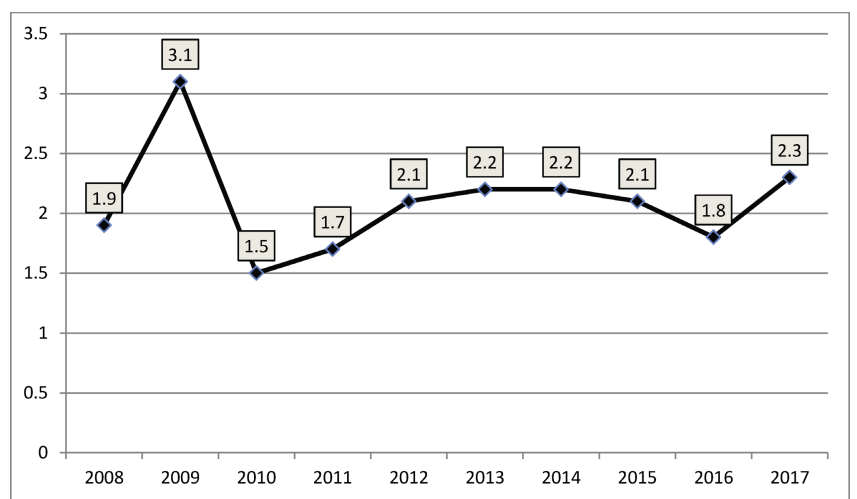

Figure 2. Mortality from EC in Tashkent from 2008 to 2017

Among 1054 patients with endometrial cancer, 81.3\% had stage I-II, $13.6 \%$ had stage III, and $5.1 \%$ had stage IV. Young age had the maximum number of patients with EC I-II stage - $62.1 \%$. In women 70 years and older, the analogous stage of the malignant process was 1.7 times less frequent - $36.7 \%$, compared with patients under 45 years old. In the study of advanced cancer, it was found that in young women of the III and IV stages of the disease were diagnosed 1.6 times less often - 11.6\%, than in patients 70 years and older - $18.6 \%$.
According to the data received, the maximum number of women died within the first three years after EC detection, which indicates the need for careful outpatient monitoring of patients in the first three years after discharge from the hospital. The five-year survival rate of patients with EC was the lowest in 2012 - 51.2\%, but from 2015 to today, the day maintains a stable rate of $62 \%$, this again proves the improvement in the quality of treatment patients with EC in recent years.

It is known that the aggressiveness index or the reliability index is determined by the ratio of mortality and morbidity and is one of the indicators of the activity of screening programs. ${ }^{7}$ The performed mathematical analysis revealed a low level of this index for uterine body cancer in the 10 -year period in the city of Tashkent $(\sim 0.05)$.
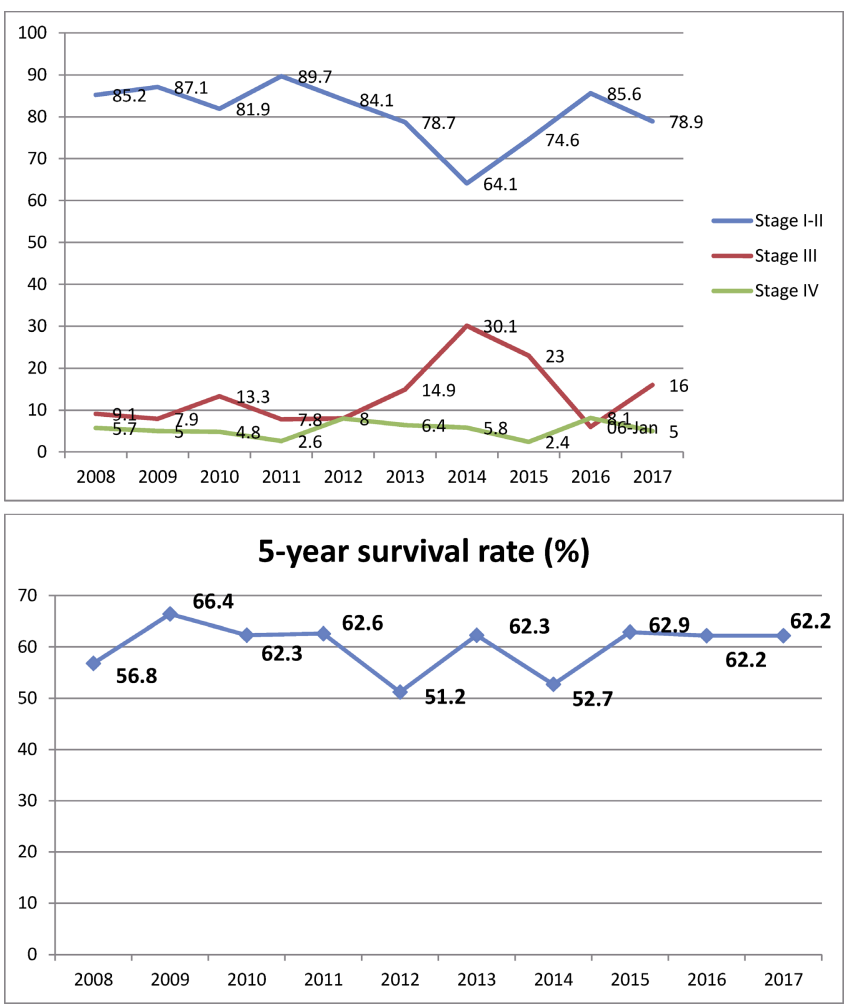

Figure 3. Distribution by stages and indicators of 5-year survival of EC from 2008 to 2017 in Tashkent.

Incidence rates for EC in 2007 increased in all age groups starting from 25 years old; they were maximum in 55-74 years (64-75\%ooo). The growth rate of morbidity with age is well characterized by the index of the accumulation of the age peak of morbidity to the level of morbidity under the age of 50 years, for example, 45-49 years old. In malignant tumors of the female genital organs, it ranged from 1.6 for cancer of the uterus. ${ }^{8}$

\section{CONCLUSION}

Thus, the incidence of EC in Tashkent in 2008-2012 increased by 1.2 times and amounted to 41.9 per 100,000 women in 2012 . The mortality of patients from EC has been constantly increasing since 2008 and reached a maximum value of 3.1 in 2009; from 2012 for the first time stable indicators were fixed -2.2 to 2017 . The indicators of 5-year survival of all EC cases in 2013-2018 yy. in Tashkent were $71.0 \pm 0.6 \%$ of patients, with EC stage I is equal to 
$83.8 \pm 0.7 \%$, with II $-73.4 \pm 1.0 \%$, with III $-39.3 \pm 2.0 \%$, at IV- 16.6 $\pm 2.4 \%$.

\section{CONFLICTS OF INTEREST}

The authors received no financial support for their research, and they report no conflicts of interest. The authors alone are responsible for the content and writing of the paper.

\section{REFERENCES}

1. http://www.cancer.org/acs/groups/content/@epidemiologysurveilance/ doECments/doECment/acspc - 027766.pdf (Globacan 2008 (IARC) Section of cancer information (6/3/2011): 3-7.
2. Sorosky JI. Endometrial cancer. Obstet Gynecol 2008; 111: 436-47.

3. Chissov VI, Starinsky VV. Gynecology by Emil Novak. 2002: 665.

4. Clinical oncogynecology. under. Ed. V.P.Kozachenko. 2005:155.

5. Chissov VI, Starinsky VV (ed.). Malignant neoplasms in Russia in 2000 (morbidity and mortality). - Moscow: MNIOI them. PA Herzen, 2002. 264.

6. Liao CK, Rosenblatt KA, Schwartz SM, Weiss NS. Endometrial cancer in Asian migrants to the United States and their descendants. Cancer Causes Control 2003; 14(4):357-60.

7. Boyle P, Ferlay J. Cancer incidence and mortality in Europe. Ann. Oncol 2005; 16:481-8.

8. Axel Evgenia Milievna. Statistics of malignant tumors of the female genital organs. Tumors of the female reproductive system. no. 1-2, 2009;76-80. 